\title{
An Empirical Analysis of Economic Growth in Hubei Province Promoted by Economic Openness Based on Three-phase DEA Model
}

\author{
Wang Zhaoyang ${ }^{1,2}$
}

(1 Jianghan university School of business, Hubei Wuhan 430056;

2 Wuhan City Circle Manufacturing Development Research Center, Hubei Wuhan 430056)

Key words: economic opening; quality of economic growth; three-stage DEA model

Abstract: This paper selected 12 major cities in Hubei as the research object and used the three-stage data envelopment analysis method to study the role of economic opening in promoting the quality of economic growth. The study results show that economic opening has a great impact on the economic growth quality of 12 cities in Hubei, but the impact of foreign trade opening and foreign capital opening on the quality of economic growth varies greatly. The main reason for the low quality of economic growth in cities in Hubei Province is the low scale efficiency, and the development of each city's economy is at the stage of increasing returns to scale, the impact of pure technical efficiency is relatively small. Based on the results of the study, the policy recommendations for improving the quality of economic growth in Hubei Province are proposed.

\section{Introduction}

Since the reform and opening up, Hubei Province has made considerable progress in its GDP and export-oriented economy. According to statistics, the regional GDP of Hubei Province has reached 3.23 trillion yuan, and the per capita GDP has reached \$8.3 thousands in 2016. At the same time, the actual use of foreign direct investment was $\$ 10.129$ billion in 2016, an increase of $13.2 \%$ over the previous year, and the total value of imports and exports was $\$ 39.398$ billion. Although there is a certain degree of decline on the basis of 2015, its absolute value remained high. General Secretary Xi Jinping clearly pointed out in the report of the 19th National Congress: "China's economy has shifted from a high-speed growth stage to a high-quality development stage." In the direction of future economic development, "the quality must be upheld, benefits must be prioritized", "promote economic development quality change, efficiency change, power change". The further integration of countries' economies under the background of economic globalization is an important feature of today's world economic development. It is also an important strategic direction for promoting our country's economy to change from a "quantity" to a "quality" development. How to use economic opening as an important path and means to improve the quality and efficiency of China's economic growth will be an important research topic that has been discussed by the academic community for a long time now and even later.

In the study of the relationship between economic opening and economic growth, the existing literature mainly focuses on the relationship between economic opening and economic aggregates, while there is less research on the relationship between economic opening and the "quality" and "benefit" of economic growth. Yang Danping and Zhang Ji (2011) $)^{[1]}$ had shown that the economic openness of Zhejiang Province has a strong positive relationship with economic growth. Therefore, we can increase the economic openness of Zhejiang Province and accelerate the economic growth of Zhejiang Province by accelerating the transformation of foreign trade growth mode, supporting 
independent innovation of export enterprises, encouraging export enterprises to open up emerging markets, and cultivating the human resources of export enterprises. Bai Yun et al (2012) ${ }^{[2]}$ believed that there was a long-term stable cointegration relationship between economic growth and openness in Hebei Province in the long-term, and opening up to the outside world will have little impact on economic growth in Hebei Province in the short-term. Hu Guozhu et al. (2014) ${ }^{[3]}$ believed that the degree of openness has a positive impact on the economic growth in southern Jiangsu and northern Jiangsu, while in the central area of Suzhou, openness contributed relatively little to the economic growth of the region, due to the slowdown in the opening process and the low performance of foreign investment. Zhang Jianqing et al (2014) ${ }^{[4]}$ found that there was a significant nonlinear relationship between trade opening and China's economic growth. The degree of trade openness had an asymmetric effect on the impact of economic growth; the promotion of trade opening on economic growth decreased as the degree of openness increases, but the two remained positively related at all times. Li Ying (2016) ${ }^{[5]}$ established fixed-effect models for the panel data of provinces in the eastern and western regions, examined the economic openness indexes affecting economic growth in the eastern and western regions of China, and discovered that import and export trade and investment in fixed assets had a positive promotion effect on economic growth, but the actual use of foreign direct investment has no obvious effect on economic growth.

This paper used three-stage DEA method to analyze the relationship between economic opening and the quality of economic growth in 12 major cities in Hubei Province. The specific approach is: use the economic development comprehensive technical efficiency to measure the quality of economic growth, use the economic openness indexes as the environmental variables and bring them into the BCC model of the data envelopment analysis method. A comparative study of the quality of economic growth before and after the inclusion of environmental variables, that is, the efficiency of economic growth, is conducted to explore the mechanism of the impact of economic opening on the quality of economic growth and the measures and methods for improving the quality of economic growth.

\section{Research Methods and Variable Selection}

\section{Research Methods}

This paper used three-stage data envelopment analysis (DEA) method to study the impact of economic opening on the economic growth quality of 12 major cities in Hubei Province. Three-stage data envelopment analysis is a new efficiency evaluation method proposed by Fried (2002) ${ }^{[6]}$, which effectively combine traditional data envelopment analysis (DEA) and stochastic frontier analysis (SFA), it overcome the drawbacks that traditional data envelopment analysis cannot measure the impact of efficiency factors and stochastic frontier analysis cannot eliminate environmental factors and random noise effects, and can more objectively reflect the quality of regional economic growth. The specific steps are as follows:

The first step is to establish an input-oriented DEA model, referred to as BCC model, under the assumption of variable returns to scale. This model was developed by Banker, Charnes, and Cooper (1984) ${ }^{[7]}$ based on the CCR model created by Charnes, Cooper, and Rhodese (1978) ${ }^{[8]}$. The specific improvement method is to adjust the assumptions, and adjust the assumptions of Constant Returns to Scale (CRS) to the Variable Returns to Scale (VRS) assumptions. This adjustment makes the model closer to the actual production. The comprehensive technical efficiency of the research unit is decomposed into pure technical efficiency and scale efficiency by the BCC model. The relationship can be expressed as: TE $=\mathrm{PTE} \times \mathrm{SE}$. In the formula, TE denotes the comprehensive technical efficiency, PTE denotes the pure technical efficiency, and SE denotes the scale efficiency. 
Since the BCC model is a fairly mature DEA model and be widely used, this article will not repeat its theoretical principles.

The second step is to build a stochastic frontier model, referred to as SFA model. The main purpose of this step is to apply the SFA model to adjust the two input variables of the original employee and the whole society's fixed asset investment after joining the economic open environment variables.

The following stochastic frontier regression equation is constructed, namely the SFA model:

$s_{i j}=f^{i}\left(z_{j} ; \beta^{j}\right)+v_{i j}+u_{i j}\left(i=1,2, \cdots m_{i j}=1,2, \cdots n\right)$, Wheres $s_{i j}$ represents the slack variable of

the ith input indicator of the jth unit. The slack variables of the input indicator are calculated by subtracting the original value of the input variable from the target value, that is, the portion that is

more than the optimal input. $\mathbf{z}_{\mathrm{j}}$ is an observable environment variable, assuming that it's a linear

combination of $\mathrm{K}$ environmental variables, $\beta^{\mathrm{j}}$ is an estimated parameter of the environmental

variable, $v_{i j}+u_{i j}$ is a compound error term of random error and internal management, and $v_{i j}$

represents a random error term, which represents random noise. $\mathrm{u}_{\mathrm{ij}}$ represents inefficient of

internal management, and $v_{i j}$ and $u_{i j}$ are independent. Defined $\gamma=\frac{\sigma_{u}^{2}}{\sigma_{v}^{2}+\sigma_{u}^{2}}$, when $\gamma$ approaches 1 , it means that internal management inefficiency plays a major role in the input slack variable. When $\gamma$ approaches 0 , it means that random noise plays a major role in the input slack variable. When $\gamma$ is between 0 and 1, both internal management inefficiencies and random errors has an effect on input slack variables.

After adding economic open environment variables, the maximum likelihood estimation is performed using the SFA regression equation with Frontier 4.1 software, and the $v_{\mathrm{ij}}+\mathrm{u}_{\mathrm{ij}}$ mixed error term is obtained. Using the formula proposed by Luo Dengyue (2012) ${ }^{[9]}$, Chen Weiwei et al $(2014)^{[10]}$, the mixed error term is decomposed, and the effects of random error and internal management inefficiency are separated:

$$
\mathrm{E}\left(\mathrm{u}_{\mathrm{ij}} \mid \mathrm{v}_{\mathrm{ij}}+\mathrm{u}_{\mathrm{ij}}\right)=\sigma_{*}\left[\frac{\varphi\left(\frac{\lambda \varepsilon}{\sigma}\right)}{\emptyset\left(\frac{\lambda \varepsilon}{\sigma}\right)}+\frac{\lambda \varepsilon}{\sigma}\right]
$$

In the formula, $\sigma_{*}=\frac{\sigma_{u} \sigma_{\mathrm{v}}}{\sigma}, \quad \sigma=\sqrt{\sigma_{u}+\sigma_{v}}, \lambda=\sigma_{u} / \sigma_{v}, \varphi$ and $\emptyset$ respectively are the density functions and distribution functions of the standard normal distribution. 
After obtaining the estimate of $u_{i j}$, the estimate of $v_{i j}$ can be further obtained.

$$
\hat{E}\left(v_{i j} \mid v_{i j}+u_{i j}\right)=s_{i j}-f^{j}\left(z_{j} ; \beta\right)-E\left(u_{i j} \mid v_{i j}+u_{i j}\right)
$$

Then use these parameter results to adjust the input variables of each decision unit. The adjustment formula is as follows:

$$
\mathrm{x}_{\mathrm{ij}}^{\mathrm{A}}=\mathrm{x}_{\mathrm{ij}}+\left[\max (\mathrm{f})^{\mathrm{j}}\left(\mathrm{z}_{\mathrm{j}} ; \beta^{\mathrm{j}}\right)-\mathrm{f}^{\mathrm{j}}\left(\mathrm{z}_{\mathrm{j}} ; \beta^{\mathrm{j}}\right)\right]+\left[\max \left(\mathrm{v}_{\mathrm{ij}}\right)-\mathrm{v}_{\mathrm{ij}}\right], \quad\left(\mathrm{i}=1,2, \cdots \mathrm{m}_{\mathrm{j}} \mathrm{j}=1,2_{s} \cdots \mathrm{n}\right)
$$

The decomposition of the mixed error term and the adjustment of the input variables are calculated by EXCLE software.

The third step is to control the DEA model after the economic opening factors.

According to the second step, replace the original input variables with the adjusted input variables that taken the economic openness as the effect factors, and the input-oriented BCC model is used again to measure the economic growth quality, the economic growth quality value obtained in the third stage is the quality value of economic growth after excluding the impact of environmental factors and random errors, this economic growth quality value is more consistent with the actual situation.

\section{Variable Selection and Description}

The data from "Hubei Statistical Yearbook" per year is collected. In order to ensure the continuity and availability of data, Wuhan, Huangshi, Shiyan, Yichang, Xiangyang, Ezhou, Jingmen, Xiaogan, Jingzhou, Huanggang, Xianning and Suizhou are selected in this paper as the research object. The study time interval is from 2006 to 2016.

According to the theory of production in economics, general factor input mainly considers labor and capital factors. Specifically, the number of employees in the entire society is used as an alternative variable to labor input. The amount of fixed capital investment in the entire society is used as an alternative variable to capital input. The GDP of 12 cities is used as an output variable. The openness of foreign trade and the degree of openness in foreign capital are used to measure the degree of economic openness in Hubei cities. The specific formula was as follows:

\section{Foreign Trade Openness = Total Imports and Exports / Gross Regional Product}

\section{Foreign Capital Openness = Use of foreign direct investment / Regional GDP}

Since the total amount of imports and exports and the use of foreign direct investment are all expressed in U.S. dollars, this paper selected the annual average value of RMB against the U.S. dollar from the "China Statistical Yearbook" to be converted into renminbi, and then calculated openness of foreign trade and openness of foreign investment.

The application of data envelopment analysis to efficiency analysis should ensure that the number of decision-making units is at least 2 times more than the total number of inputs and outputs [11]. The object of this study is 12 cities in Hubei Province, and the number of decision-making units (DMU) is 12. The number of input indicators (financial capital investment in the entire society and the number of employees in the entire society) and output indicators (the city's regional production value) is 3 , the decision-making unit is 4 times the amount of the input and output indicators. Therefore, it is suitable to apply the DEA method. At the same time, in order to avoid the decrease 
in the number of output indicators caused by the increase in the number of input indicators, the DEA model also requires a significant positive correlation between input variables and output variables ${ }^{[11]}$. The calculated correlation coefficient between the GDP of the cities of Hubei Province and the labor force and the fixed assets investment of the whole society respectively is 0.9175 and 0.9751 , and the input and output selected in this paper are tested at the $1 \%$ level of significance. The indicators have a significant positive correlation, which proves that the use of data envelopment analysis methods to measure the quality of economic growth in Hubei Province is reasonable once again.

\section{Data Measurement and Empirical Test}

\section{The First Stage BCC Model Analysis Results}

The DEAP 2.1 software is used to measure the economic growth quality of 12 major cities in Hubei Province and the results are shown in Table 1. The average integrated technical efficiency of economic growth in 12 cities in Hubei Province during 2006-2016 was 0.776, the average value of pure technological efficiency is 0.886 , and the average scale efficiency is 0.879 , indicate that the quality of economic growth in 12 cities in Hubei Province is not too high. The pure technical efficiency of most cities is greater than the scale efficiency. The average pure technical efficiency of Wuhan and Suizhou is only 1, which is in the optimal state, accounts for only $16.67 \%$ of the decision-making units. The average of pure technical efficiency and scale efficiency of other cities is less than 1, which indicate that the overall quality of economic development of Hubei Province is not high and there is an ample room for improvement.

Table 1 Average Economic Efficiency of 12 Cities Before and After the Elimination of Environmental and

\begin{tabular}{|c|c|c|c|c|c|c|}
\multicolumn{2}{|c|}{ City } & \multicolumn{3}{|c|}{ Sefore Adjustment } & \multicolumn{3}{c|}{ After Adjustment } \\
\cline { 2 - 7 } & TE1 & PTE1 & SE1 & TE2 & PTE2 & SE2 \\
\hline Wuhan & 0.897 & 1.000 & 0.897 & 1.000 & 1.000 & 1.000 \\
\hline Huangshi & 0.750 & 0.845 & 0.890 & 0.497 & 0.921 & 0.525 \\
\hline Shiyan & 0.831 & 0.961 & 0.865 & 0.530 & 0.978 & 0.531 \\
\hline Yichang & 0.882 & 0.928 & 0.950 & 0.749 & 0.929 & 0.765 \\
\hline Xiangyang & 0.926 & 0.964 & 0.959 & 0.769 & 0.940 & 0.778 \\
\hline Ezhou & 0.677 & 0.851 & 0.820 & 0.407 & 0.997 & 0.408 \\
\hline Jingmen & 0.775 & 0.879 & 0.886 & 0.494 & 0.967 & 0.499 \\
\hline Xiaogan & 0.629 & 0.812 & 0.776 & 0.443 & 0.926 & 0.470 \\
\hline Jingzhou & 0.672 & 0.716 & 0.941 & 0.496 & 0.920 & 0.523 \\
\hline Huanggang & 0.580 & 0.823 & 0.735 & 0.421 & 0.881 & 0.456 \\
\hline Xianning & 0.712 & 0.855 & 0.846 & 0.370 & 0.988 & 0.371 \\
\hline Suizhou & 0.983 & 1.000 & 0.983 & 0.374 & 0.996 & 0.375 \\
\hline Mean & 0.776 & 0.886 & 0.879 & 0.546 & 0.954 & 0.558 \\
\hline
\end{tabular}

\section{The Second Stage SFA Regression Analysis Results}

The slack variables of each input variable of the first stage decision units are taken as the explained variables, and the foreign trade openness and foreign capital openness are used as explanatory variables to conduct random frontier regression analysis. The results are shown in Table 2 by using Frontier4.1 measurement software. From Table 2, we can see that in the models of 
two input slack variables, the degree of foreign trade openness and foreign capital openness passed the significance test at the level of $1 \%$ or $10 \%$ significance, and it can be considered that the degree of openness in foreign trade and the degree of openness in foreign capital affect the economic growth quality of Hubei cities more than random noise items and management inefficiency. Moreover, the LR unilateral tests of both models passed the test at 5\% significance; we should reject the null hypothesis of $\gamma=0$, which indicates that the second stage SFA was necessary.

Table 2 The Second Step SFA Model Regression Estimation Analysis

\begin{tabular}{|c|c|c|c|c|}
\hline \multirow{2}{*}{ Variables } & \multicolumn{2}{|c|}{ Employees' slack value } & \multicolumn{2}{|c|}{$\begin{array}{l}\text { The slack value of investment in fixed assets in the } \\
\text { whole society }\end{array}$} \\
\hline & $\begin{array}{c}\text { coefficie } \\
\mathrm{nt}\end{array}$ & $\begin{array}{l}\text { Standard } \\
\text { deviation }\end{array}$ & coefficient & Standard deviation \\
\hline Constant term & 2.419 & 2.021 & 65.901 & 24.765 \\
\hline $\begin{array}{l}\text { Openness of foreign } \\
\text { trade }\end{array}$ & $\begin{array}{c}-55.726 * \\
* *\end{array}$ & 15.407 & $-758.321^{* * *}$ & 225.354 \\
\hline $\begin{array}{l}\text { Openness of foreign } \\
\text { investment }\end{array}$ & $\begin{array}{c}124.919 \\
*\end{array}$ & 86.432 & $-287.839 *$ & 179.071 \\
\hline Sigma-squared & $\begin{array}{c}172.475 \\
* * *\end{array}$ & 55.010 & $33863.565^{* * *}$ & 70.429 \\
\hline gamma & $0.618 * * *$ & 0.126 & $0.548 * * *$ & 0.057 \\
\hline Log likelihood function & \multicolumn{2}{|c|}{-475.1705} & \multicolumn{2}{|c|}{-835.1706} \\
\hline $\begin{array}{l}\text { LR test of the one- sided } \\
\text { error }\end{array}$ & \multicolumn{2}{|c|}{40.1057} & \multicolumn{2}{|c|}{28.8770} \\
\hline
\end{tabular}

Note: The ${ }^{* * *}, * *$ and $*$ respectively represent significant levels at $1 \%, 5 \%$ and $10 \%$

From Table 2, we can see that in both models, the coefficient of openness of foreign trade is negative, which indicates that the degree of openness in foreign trade is inversely related to the redundant variables of the input of the employees and the whole society's fixed asset investment. That is, the increase in the degree of openness in foreign trade will lead to a reduction in the two input variables of the fixed assets investment of employees and the whole society, which will improve the quality of economic growth in various regions of Hubei Province. Therefore, we can improve the quality of economic growth in various regions of Hubei Province by increasing the openness of foreign trade.

The degree of openness in foreign capital is positive in one model and negative in another one. The degree of openness in foreign capital is positive in the redundant variables of employees, which means that the increase in openness of foreign capital will increase the input of employees and reduce the economic growth quality of 12 major cities in Hubei Province. The opening degree of foreign capital is negative in the whole society's fixed asset investment redundancy variable. It shows that the increase in the degree of openness of foreign capital will reduce the investment of social fixed investment in the whole society and improve the economic growth quality of major cities in Hubei Province. In this regard, our explanation is as follows: The foreign direct investment industry is not a technology or capital-intensive industry, mainly in labor-intensive industries; at the same time, foreign direct investment has a significant "crowding-out effect" on domestic investment, that is, foreign direct investment has strong repetitiveness with domestic capital investment directions and fields. 
In addition, the gamma coefficients between labor and capital input slack variables, foreign trade openness, and foreign capital openness respectively are 0.618 and 0.548 , and passed the test at a $1 \%$ level of significance, which indicates that gamma is between 0 and 1 . It shows that the compound error term is affected by both the inefficient and stochastic noise management factors ${ }^{\text {[12] }}$. Further explanation is that it is necessary to adjust the input variables for the second stage of adjustment.

\section{The Third Stage BCC Analysis Results}

Based on the adjusted input variable data in the second stage, the BCC model was used to measure the economic growth of 12 cities in Hubei again. The results are shown in Table 1.

As is shown in Table 1, the quality of economic and economic growth in 12 cities in Hubei has a large gap before and after removing environmental factors and random errors. Overall, the average value of the first stage of comprehensive technical efficiency measurement drops from 0.776 to 0.546 in the third stage, and the average value of pure technical efficiency increases from 0.886 to 0.954 , but the number of cities with effective pure technical efficiency is reduced from 2 to 1. The scale efficiency falls from 0.879 measured in the first stage to 0.558. Obviously, after eliminating the impact of the opening of foreign trade and the opening up of foreign investment and the impact of random noise, the pure technical efficiency of Hubei's economic development has increased by $7.60 \%$, but its scale efficiency and comprehensive technical efficiency has decreased significantly, and the dropped rate is as high as $36.46 \%$ and $29.67 \%$.

The following is a detailed analysis of the results of the third stage DEA analysis.

(1) Analysis of Comprehensive Technical Efficiency

From Table 1, we can see that the quality of economic growth in the 12 cities in Hubei changes greatly after the adjustment. Except for Wuhan, the adjusted economic growth of the other 11 cities is lower than the quality of economic growth before adjustment. Specifically, in the calculation of economic efficiency before adjustment, no decision-making unit is at the front of production; Wuhan City, which is the only one that at the front of economic efficiency after adjustment, shows that Wuhan is both efficient in technical efficiency and scale efficiency. Wuhan City is the only one that has improved its overall technical efficiency after adjustment. This shows that the development of Wuhan's export-oriented economy has greatly improved the quality of economic growth in the city.

(2) Pure Technical Efficiency Analysis

From Table 1, it can be seen that the adjusted pure technical efficiency value basically shows greater than the pure technical efficiency value before adjustment, and is contrary to the direction of changes in the overall technical efficiency and scale efficiency. Specifically, only two cities, Suizhou and Xiangyang, where the efficiency of pure technology become smaller after adjustments, and Wuhan has no changes since it is on the front line of production all time before and after the adjustment. The other nine cities have become larger, among them, the Jingzhou increases largest, reaches 28.49\%, followed by Ezhou, Xianning and Xiaogan. It shows that there is a strong relationship between the low level of pure technical efficiency before adjustment and random noise and the low level of economic openness.

\section{(3) Analysis of Scale Efficiency}

According to the BCC model, the scale efficiency value equal to 1 means that it in the optimal state of scale returns, and less than 1 means that the scale compensation does not reach the optimal state, and it is in the stage of diminishing returns to scale or increasing returns. From Table 1 , we can see that most of the city's adjusted scale efficiency value is less than the value before adjustment. Only Wuhan, Yichang, and Xiangyang with adjusted scale efficiency values greater 
than 0.7, and Ezhou, Jingmen, Xiaogan, Huanggang, Xianning, and Suizhou are less than 0.5. The efficiency of pure technology has increased, and the overall technical efficiency has dropped sharply. This shows that the low economic efficiency of cities in Hubei is mainly caused by the low scale efficiency. Table 3 and 4 show the stage of scale compensation for 12 cities before and after adjustment in Hubei. From Table 3, we can see that before adding economic openness indicators as environmental variables for adjustment, except Wuhan, Huangshi, Liyang, Xianning, and Suizhou cities, which appear in the best-scale rewards in a few years, other cities are basically in effective state, and most cities are in the stage of increasing returns to scale. After adjust by adding economic opening indicators, except for Wuhan being on the production frontier of scale economy, the other 11 cities are all in the stage of increasing returns to scale, which indicates that the main reason for the low economic efficiency of Hubei Province is caused by insufficient input.

Table 3 Results of Scale Compensation Survey of 12 Cities in Hubei Province Before Adjustment in 2006-2016

\begin{tabular}{|c|c|c|c|c|c|c|c|c|c|c|c|}
\hline City & 2006 & 2007 & 2008 & 2009 & 2010 & 2011 & 2012 & 2013 & 2014 & 2015 & 2016 \\
\hline Wuhan & drs & drs & drs & drs & drs & drs & - & - & - & - & - \\
\hline Huangshi & drs & drs & drs & irs & irs & irs & irs & irs & irs & irs & irs \\
\hline Shiyan & drs & drs & - & - & irs & irs & irs & irs & irs & irs & irs \\
\hline Yichang & irs & drs & drs & irs & drs & drs & irs & irs & irs & irs & irs \\
\hline Xiangyang & - & drs & drs & - & - & - & irs & irs & irs & irs & irs \\
\hline Ezhou & drs & drs & drs & irs & irs & irs & irs & irs & irs & irs & irs \\
\hline Jingmen & irs & irs & irs & irs & irs & irs & irs & irs & irs & irs & irs \\
\hline Xiaogan & irs & irs & irs & irs & irs & irs & irs & irs & irs & irs & irs \\
\hline Jingzhou & irs & irs & irs & irs & irs & irs & irs & irs & irs & irs & irs \\
\hline Huanggang & irs & irs & irs & irs & drs & irs & irs & irs & irs & irs & irs \\
\hline Xianning & irs & irs & irs & irs & irs & irs & irs & irs & - & drs & drs \\
\hline Suizhou & - & - & - & irs & - & - & - & irs & - & - & - \\
\hline
\end{tabular}

Note: The irs, drs and - respectively represent increase, decrease and constant

Table 4 Results of Scale Compensation Survey of 12 Cities in Hubei Province After Adjustment in 2006-2016

\begin{tabular}{|c|c|c|c|c|c|c|c|c|c|c|c|}
\hline City & 2006 & 2007 & 2008 & 2009 & 2010 & 2011 & 2012 & 2013 & 2014 & 2015 & 2016 \\
\hline Wuhan & - & - & - & - & - & - & - & - & - & - & - \\
\hline Huangshi & irs & irs & irs & irs & irs & irs & irs & irs & irs & irs & irs \\
\hline Shiyan & irs & irs & irs & irs & irs & irs & irs & irs & irs & irs & irs \\
\hline Yichang & irs & irs & irs & irs & irs & irs & irs & irs & irs & irs & irs \\
\hline xiangyang & irs & irs & irs & irs & irs & irs & irs & irs & irs & irs & irs \\
\hline Ezhou & irs & irs & irs & irs & irs & irs & irs & irs & irs & irs & irs \\
\hline Jingmen & irs & irs & irs & irs & irs & irs & irs & irs & irs & irs & irs \\
\hline Xiaogan & irs & irs & irs & irs & irs & irs & irs & irs & irs & irs & irs \\
\hline Jingzhou & irs & irs & irs & irs & irs & irs & irs & irs & irs & irs & irs \\
\hline Huanggang & irs & irs & irs & irs & irs & irs & irs & irs & irs & irs & irs \\
\hline Xianning & irs & irs & irs & irs & irs & irs & irs & irs & irs & irs & irs \\
\hline Suizhou & irs & irs & irs & irs & irs & irs & irs & irs & irs & irs & irs \\
\hline
\end{tabular}

Note: The irs, drs and - respectively represent increase, decrease and constant 


\section{The Main Conclusions and Policy Recommendations}

The main conclusions of this paper are as follows:

First, the quality of economic development in Hubei Province is greatly influenced by the openness of foreign trade and the degree of openness of foreign investment. Excluding the influence of two environmental variables, the opening of foreign trade and the opening of foreign capital, the quality of economic development in all regions has dropped significantly.

Second, the main reason affecting the quality of economic development in Hubei Province is scale efficiency. The efficiency of economic scale after adjustment in most cities is significantly lower than purely technical efficiency.

Third, the areas of ineffective economic growth after adjustment are all in the stage of increasing returns to scale.

Fourth, the overall economic development of the adjusted Hubei Province is generally low. After adjustment, only one city, Wuhan, has a relatively good input-output efficiency. The other 11 cities' input-output pure technical efficiency and scale efficiency need to be improved.

Based on the above studies, we can see that the quality of economic growth in cities in Hubei Province is not optimistic. In the process of improving the quality of economic growth in cities, first, the impact of economic opening on improving the quality of economic growth must be fully considered. While maintaining the steady growth of exports, all cities in Hubei must accelerate the upgrading of the growth mode of import and export trade and the change in the structure of export products, and strive to increase the proportion of capital-intensive, especially technology-intensive, commodities in export commodities. Governments at all levels should focus on increasing the quality and comprehensive efficiency of attracting foreign investment in attracting foreign direct investment, pay attention to the introduction of high-tech foreign investment projects, try to avoid overlapping with the domestic capital investment field, and reduce the "crowding-out effect" of foreign capital on domestic capital. Second, cities in Hubei Province should increase investment, expand the economic scale of the city, and increase the current level of technical efficiency at a relatively low level, thereby improving the quality of economic growth. Third, we must give full play to the leading and radiation role of Wuhan City, promote the balanced and coordinated development of Hubei's regional economy, and try to avoid the phenomenon of "outstanding" in the process of economic development.

\section{Acknowledgements}

This work was financially supported by Direct Foundation of Wuhan City Circle Manufacturing Development Research Center (WZ2017J03)

\section{References:}

[1] Yang Danping, Zhang Ji. The Impact of Economic Openness on Economic Growth: An Empirical Test Based on Data from 1992-2009 in Zhejiang Province [J]. International Trade Issues, 2011(6): 101-110

[2] Bai Yun, Feng Xiaoning, Jia Juan. An Empirical Study of Openness and Economic Growth: A Cointegration Analysis of Hebei Province Data [J]. Academic Exploration, 2012, (9): 64-66

[3] $\mathrm{Hu}$ Guozhu, Zheng Wenqing, et al. Regional differences in the relationship between openness and economic growth in Jiangsu Province[J]. East China Economic Management, 2014(11): 5-10 
[4] Zhang Jianqing, Jiang Tan. Non-linear relationship between trade opening and economic growth: Theory and empirical research in China[J]. World Economic Review, 2014(5): 27-52

[5] Li Ying. An Empirical Test of the Relationship between Economic Openness and Economic Growth in the Eastern and Western Provinces of China [J]. Statistics and Decision, 2016(22): 133-135

[6] Fried, Lovell, Schmidt, Yaisa Warng. Accounting for Environmental Effects Statistical Noise in Data Envelopment Analysis [J]. Journal of Productivity Analysis, 2002,(17): 121-136

[7] Banker,R.D., A. Charners and W. W. Cooper. Some Models for Estimating Technical and Scale Inefficiencies in Data Envelopment Analysis[J]. Management Science,1984,(30): 1078-1092

[8] Charnes, A., W. W. Cooper and E. Rhodes. Measuring the Efficiency of Decision Making Unites[J]. European Journal of Operational Research, 1878,(2): 429-444

[9] Luo Dengyue. Note on the Inefficiency Estimation of Three-stage DEA Model Management[J]. Statistical Research, 2012, (4): 104-107

[10] Chen Hao, Zhang Lei, et al. Some researches on the three-stage DEA model[J]. System Engineering, 2014,(9): 144-149

[11] Jiang Ping, Wang Yong. Research on Input and Output Efficiency of Full-caliber Chinese Cultural Industry__ Analysis based on the Three-phase DEA Model and Super-efficiency DEA Mode [J]. Journal of Quantitative Economics and Technology Economics,2011,(12): 69-81

[12] Guo Junhua, Ni Ming, Li Bangyi. Research on Agricultural Productivity Based on Three-stage DEA Model [J]. Journal of Quantitative Economics and Technology Economics, 2010, (12): 27-38 